\title{
Representação Social da Qualidade de Vida Após o Estoma Intestinal pelo Paciente com Neoplasia Colorretal
}

\section{Social Representation of the Life Quality After the Intestinal Stoma by the Patient with Colorectal Neoplasm}

\author{
Renata Queiroz Batista ${ }^{1}$ \\ Raquel de Souza Ramos ${ }^{2}$ \\ Margarida Maria Rocha Bernardes 3 \\ Cibele Aquino Barbosa 4 \\ Juliana Maximo da Costa ${ }^{5}$
}

\footnotetext{
${ }^{1}$ Enfermeira. Residente em Oncologia pelo Instituto Nacional do Câncer José Alencar Gomes da Silva (INCA). Docente da Faculdade Vale do Cricaré. Espírito Santo, Brasil. E-mail: renata_qbatista@hotmail.com. Autor correspondente.

${ }^{2}$ Enfermeira. Doutora em Enfermagem pela Universidade do Estado do Rio de Janeiro (UERJ). Enfermeira do Hospital Universitário Pedro Ernesto (HUPE) e do Instituto Nacional do Câncer José Alencar Gomes da Silva (INCA). Rio de Janeiro, Brasil. E-mail: rramos@inca.gov.br.

${ }^{3}$ Enfermeira. Doutora em Enfermagem pela Universidade do Estado do Rio de Janeiro (UERJ). Pós-Doutoranda do Programa de Mestrado da Universidade Federal do Estado do Rio de Janeiro (UNIRIO). Docente do Centro Universitário Augusto Motta (UNISUAM). Rio de Janeiro, Brasil. E-mail: margarbe@globo.com.

${ }^{4}$ Médica. Mestre em Saúde Coletiva pela Universidade Federal Fluminense (UFF). Cirurgiã oncológica do Instituto Nacional do Câncer José Alencar Gomes da Silva (INCA). Rio de Janeiro, Brasil. E-mail: cibele.barbosa@inca.gov.br.

${ }^{5}$ Enfermeira. Residente em Oncologia pelo Instituto Nacional do Câncer José Alencar Gomes da Silva (INCA). Especialista em Estomaterapia e em Clínica Cirúrgica pela Universidade do Estado do Rio de Janeiro (UERJ). Rio de Janeiro, Brasil. E-mail: enfamaximo@gmail.com.
} 


\title{
Resumo
}

Objetiva-se analisar a representação social da qualidade de vida após a confecção de um estoma intestinal pelos pacientes oncológicos, além de identificar a estrutura das representações sociais da qualidade de vida após a confecção de um estoma intestinal pelos pacientes oncológicos e discutir as possíveis repercussões dessas representações no planejamento da assistência de enfermagem nesse grupo social. Estudo descritivo, de natureza qualitativa, pautado na Teoria das Representações Sociais. Foram abordados 80 pacientes e a técnica para coleta de dados foi a da evocação livre, com os termos indutores "qualidade de vida antes da colostomia" e "qualidade de vida após a colostomia", sendo tratado pelo software Ensemble de programmes permettant l'analyse dês evocations (EVOC). A Representação Social da qualidade de vida após a confecção de um estoma mostrou elementos negativos, assim como a qualidade de vida antes do estoma, mostrou elementos positivos. Fazendo uma breve comparação, foi claramente possível ver suas diferenças, principalmente em relação aos sentimentos, suas limitações, seus hábitos alimentares, seus medos e estigmas. Faz-se necessário a implantação e permanência de uma equipe multidisciplinar que vise à reinserção social, fornecendo estratégias para melhor adaptação da sua nova condição de vida, repriorizando valores e metas.

Palavras-chave: Percepção Social; Neoplasias Colorretais; Colostomia.

\begin{abstract}
The aim of this study was to analyze the social representation of life quality of after the preparation of an intestinal stoma by oncological patients, as well as to identify the structure of the social representations of life quality after the preparation of an intestinal stoma by cancer patients and to discuss the possible repercussions of these representations in nursing care planning in this social group. Descriptive study, of qualitative nature, based on the Theory of Social Representations. Eighty patients were approached and the technique for data collection was that of free evocation, with the terms "quality of life before colostomy" and "quality of life after colostomy", being treated by software Ensemble de programs permettant l'analyze of evocations (EVOC). The Social Representation of life quality after the manufacture of a stoma showed negative elements, as well as the life quality before the stoma, showed positive elements. By making a brief comparison, it was clearly possible to see their differences, especially in relation to their feelings, limitations, eating habits, fears and stigmata. It is necessary the implantation and permanence of a multidisciplinary team that aims at social reintegration, providing strategies to better adapt to their new living conditions, reprioritizing values and goals.
\end{abstract}

Keywords: Social Perception; Colorectal Neoplasms; Colostomy. 


\section{Introdução}

Desde 1903, o câncer é problema de saúde pública mundial. Destaca-se que nesta época não havia centros e profissionais especializados, para diagnóstico e tratamento deste agravo, o que tornava mais grave este problema de saúde ${ }^{(1)}$.

Hoje em dia, com toda a tecnologia que possuímos para o diagnóstico precoce e tratamento, as perdas de vida associadas a esta doença ainda persistem, sendo o câncer responsável por 8,2 milhões de óbito no mundo todo, em 2012(2). No mundo, o câncer de cólon e reto configura-se como o terceiro tipo de câncer mais comum entre os homens $(10,0 \%)$, e o segundo nas mulheres, $(9,2 \%)^{(2)}$.

No grupo de tumores de cólon e reto, o tratamento é normalmente cirúrgico, sendo frequente a necessidade de confecção de um estoma intestinal. Estes estomas podem ser temporários ou definitivos e, basicamente, estão indicados para evitar que as fezes passem pela região do intestino manipulada pelo procedimento cirúrgico antes da completa cicatrização das anastomoses, prevenindo, assim, infecções ou deiscência nos locais suturados, ou para servir como via permanente de eliminação de fezes em cirurgias em que haja ressecção de reto baixo ou do ânus ${ }^{(3)}$.

Uma em cada 10 mil pessoas é estomizada no mundo. Já no Brasil, estima-se que 1,4 milhões de pessoas utilizam o equipamento coletor em decorrência de estomias intestinais e urinárias ${ }^{(4)}$.

A vivência de um câncer e de uma colostomia muda permanentemente a vida diária do sujeito e constitui um dos momentos mais críticos da vida de uma pessoa, por implicar um sistema complexo de análise e reflexão da própria biografia, cujos significados foram construídos ao longo das suas experiências de vida(5).

Apesar de ter sido desenvolvida como uma estratégia para prolongar a sobrevida e promover melhor qualidade de vida às pessoas, as estomias são agressivas e mutilantes em todo o processo de viver humano, resultando em sentimentos de repugnância de si mesmo e desprestígio social(5).

Este trabalho surgiu de uma inquietação gerada durante a assistência às pessoas que tinham sido submetidas a uma intervenção cirúrgica da qual resultava um estoma. A assistência não é apenas a realização de orientações acerca dos cuidados com o estoma e com os equipamentos. Sendo assim, no sentido de compreender melhor a realidade do cotidiano da pessoa estomizada, analisando sua representação social acerca da qualidade de vida após o estoma, que se propôs a realização desta pesquisa.

Este estudo pode gerar contribuições que abarcam o trabalho desenvolvido não apenas pelos enfermeiros, mas também a equipe multiprofissional que o assiste e, principalmente, o cliente. Na medida em que se conhece melhor a representação desses sujeitos sobre a qualidade de vida após a confecção de um estoma intestinal, surge a possibilidade de propor estratégias para qualificar a assistência e para sensibilizar os demais profissionais da equipe multiprofissional sobre a importância da compreensão do senso comum objetivando uma reabilitação plena e a qualidade de vida destes sujeitos.

Desta forma, a pesquisa tem como objetivo, analisar a representação social da qualidade de vida após a confecção de um estoma intestinal pelos pacientes oncológicos, além de identificar a estrutura das representações sociais da qualidade de vida após a confecção de um estoma intestinal pelos pacientes oncológicos e discutir as possíveis repercussões dessas representações no planejamento da assistência de enfermagem nesse grupo social

\section{Método}

Optou-se por um estudo descritivo, de natureza qualitativa, pautado na Teoria das Representações Sociais, que segundo Moscovici(5), é "uma modalidade de conhecimento particular que tem por função a elaboração de comportamentos e a comunicação entre os indivíduos".

A pesquisa foi realizada no ambulatório de estomaterapia de um instituto público de referência nacional em pesquisa, ensino e assistência em oncologia na cidade do Rio de Janeiro, enquanto os pacientes aguardavam atendimento. No período compreendido entre março e outubro de 2016. 
A população foi composta por pacientes acompanhados no setor de estomaterapia. Para poder compreender a estrutura da representação social, foram abordados 80 estomizados em decorrência de neoplasia de cólon e reto em acompanhamento na unidade. Os critérios de inclusão foram: ser estomizado definitivo por câncer colorretal; maiores de 18 anos; aceitar participar da pesquisa.

Para realizar a coleta de dados, foi utilizado um questionário sociodemográfico de caracterização dos participantes e aplicação da técnica de evocação livre. Esta técnica permite ao sujeito falar e escrever palavras, adjetivos ou expressões que lhes ocorram, após ser estimulado por um termo indutor e assim alocá-los na ordem que lhe vier à mente. Para este estudo foram aplicados dois termos indutores "qualidade de vida antes da colostomia" e "qualidade de vida após a colostomia" ao qual foi solicitada a associação de cinco palavras ${ }^{(6-7)}$.

A análise foi feita através do tratamento estatístico simples dos dados sociodemográficos pelo software Excel e análise das evocações livres pelo software Ensemble de programmes permettant l'analyse dês evocations (EVOC), que é um programa de informática que organiza as palavras evocadas por ordem de frequência e média de evocação, que permite a construção do quadro de quatro casas que facilitará a organização dos dados para sua posterior análise e discussão ${ }^{(7)}$.

Este estudo foi submetido ao comitê de ética e pesquisa, sendo aprovado pelo parecer 1.529.624 e o mesmo encontra-se em consonância com o estabelecido na Resolução n. $.9466 / 12$ do Conselho Nacional da Saúde e suas complementares. Os participantes foram orientados acerca dos objetivos da pesquisa e quanto à assinatura do Termo de Consentimento Livre e Esclarecido (TCLE), o qual foi lhes garantido $\mathrm{o}$ anonimato.

\section{Resultados e Discussão}

A seguir serão apresentados os resultados encontrados através das entrevistas com 80 pacientes estomizados, atendidos no ambulatório de estomaterapia.

Tabela 1. Distribuição dos pacientes estomizados, segundo as características sociodemográficas. Rio de Janeiro, RJ, Brasil, 2016.

\begin{tabular}{c|c|c}
\hline Sexo & $\mathrm{F}$ & $\%$ \\
\hline Feminino & 42 & 52,5 \\
Masculino & 38 & 47,5 \\
\hline Faixa etária & & \\
\hline \multirow{2}{*}{$18-35$} & 05 & 6,25 \\
$37-49$ & 14 & 17,5 \\
50 ou mais & 61 & 76,25 \\
\hline Estado Civil & & \\
\hline Solteiro & 20 & 25 \\
Casado & 38 & 47,5 \\
Separado & 7 & 8,75 \\
Viúvo & 15 & 18,75 \\
\hline Grau de Instrução & & \\
\hline
\end{tabular}




\begin{tabular}{c|c|c}
\hline & & \\
Analfabeto & 3 & 3,75 \\
Funcional & 35 & 43,75 \\
Ensino fundamental & 34 & 42,5 \\
Ensino médio & 7 & 8,75 \\
Ensino superior & 1 & 1,25 \\
Pós-graduação & & \\
\hline Religião & & \\
\hline Católico & 43 & 53,75 \\
Evangélico & 28 & 35 \\
Messiânico & 1 & 1,25 \\
Espírita & 2 & 2,5 \\
Sem religião & 6 & 7,5 \\
& &
\end{tabular}

Fonte: dados da pesquisa.

Esta tabela mostra que a porcentagem entre homens e mulheres está equilibrada, sendo do sexo feminino, $52,5 \%$, e $47,5 \%$ do sexo masculino. Segundo as estimativas do INCA ${ }^{(2)}$, as mulheres tem um risco maior de desenvolver este tipo de neoplasia, com um risco estimado de 17,10/100.000 mulheres e 16,84/100.000 homens.

Com relação a idade $76,25 \%$ possui 50 anos ou mais, enquanto que $17,5 \%$ possui idade entre 37 e 49 anos e apenas $6,25 \%$ possui idades entre 18 e 36 anos. Desta forma, percebe-se que a população com idade avançada é a mais acometida por esta neoplasia, corroborando com pesquisas que dizem que em indivíduos com mais de 50 anos, o aumento da incidência pode ser exponencial(8).

Já em relação ao estado civil, 47,5\% são casados, seguido por $25 \%$ solteiros, $18,75 \%$ são viúvos e $8,75 \%$ separados. Esses dados acabam se tornando importantes, quando consideramos o companheiro como um apoio para o enfrentamento do estado atual e para segurança emocional, uma vez que a qualidade de vida está ligada ao estado emocional de qualquer pessoa ${ }^{(9)}$.
Quanto ao grau de instrução a tabela nos mostra que, $43,75 \%$ dos entrevistados possuem o ensino fundamental, $42,5 \%$ possuem o ensino médio, 8,75\% possuem o ensino superior, 3,75 são analfabetos funcionais e apenas $1,25 \%$ possuem a pós-graduação. É importante salientar que uma baixa escolaridade, é um dado importante, pois quanto menor for o grau de instrução desse sujeito maior vai ser a dificuldade relacionada ao acesso e ao conhecimento sobre o processo da doença e de seu tratamento ${ }^{(10)}$.

Já em relação a religião $53,75 \%$ dos entrevistaram se dizem católicos, 35\% evangélicos, seguidos por $7,5 \%$ que disseram não ter religião, $2,5 \%$ se declararam espírita e $1,25 \%$ são messiânicos. Sendo assim, percebemos que os valores, crenças e atitudes, são conceitos importantes que norteiam a vida e o comportamento do ser estomizado, auxiliando no retorno às atividades da vida diária e favorecendo o processo de reabilitação ${ }^{(11)}$.

Tabela 2. Distribuição dos pacientes estomizados, de acordo com a situação de saúde após a ostomia. Rio de Janeiro, RJ, Brasil, 2016.

\begin{tabular}{c|l|l}
\hline $\begin{array}{c}\text { Tempo de } \\
\text { Cirurgia }\end{array}$ & $F$ & $\%$ \\
\hline $1-7$ anos & 70 & 87,5 \\
$8-19$ anos & 9 & 11,25
\end{tabular}




\begin{tabular}{l|l|l} 
mais anos ou & 1 & 1,25 \\
\hline Tipo de & & \\
estoma & & 85 \\
Colostomia & 68 & 15
\end{tabular}

Fonte: dados da pesquisa.

Em relação ao tempo de cirurgia, 87,5 \% dos entrevistados tinham entre 1 e 7 anos, $11,25 \%$ tinham entre 8 e 19 anos e apenas 1,25\% tinha 20 anos ou mais. Quanto mais recente a cirurgia para a realização do estoma, maiores são as dificuldades encontradas por essa população, para se manejarem as novas necessidades e maiores são os constrangimentos sofridos pelas pessoas ${ }^{(12)}$.

E quanto ao tipo de ostomia $85 \%$ possuem colostomia e 15\% íleostomia. A realização de um estoma intestinal está intimamente relacionado à cirurgia proposta para o tratamento do fator causal, nesse estudo a causa predominante foi neoplasia colorretal ${ }^{(11)}$.

A partir da análise através do quadro de quatro casas com o apoio do software EVOC 2005 com o termo indutor "qualidade de vida antes da colostomia", foi possível identificar os possíveis elementos centrais, de contraste e periféricos da representação social da qualidade de vida antes o estoma pelo paciente com neoplasia colorretal.

Foram evocadas 800 palavras, sendo 115 diferentes. A média das ordens médias de evocação (OME), ou seja, o score foi igual a 2,8, ao passo que a frequência média ficou estabelecida em 13 e a mínima em 12. A análise combinada desses dados resultou no quadro de quatro casas apresentado a seguir (Quadro 1).

Quadro 1. Estrutura da representação social da qualidade de vida antes da colostomia. Rio de Janeiro, RJ, Brasil, 2016.

\begin{tabular}{|c|c|c|c|c|c|c|}
\hline \multicolumn{7}{|c|}{ OME $(n=80)$} \\
\hline \multicolumn{4}{|c|}{$<2,8$} & \multicolumn{3}{|c|}{$\geq 2,8$} \\
\hline \multirow{2}{*}{$\begin{array}{l}\text { Frequência } \\
\text { média }\end{array}$} & $\begin{array}{l}\text { Termos } \\
\text { evocados }\end{array}$ & \multirow[t]{2}{*}{$\mathrm{F}$} & \multirow[t]{2}{*}{ OME } & Termos evocados & \multirow[t]{2}{*}{$\mathrm{F}$} & \multirow[t]{2}{*}{ OME } \\
\hline & $\begin{array}{l}\text { Elementos } \\
\text { centrais }\end{array}$ & & & Primeira periferia & & \\
\hline \multirow{6}{*}{$\geq 12$} & Boa & 35 & 1,943 & Alegre & 17 & 3,471 \\
\hline & Melhor & 21 & 2,524 & Apoio-familiar & 17 & 3,588 \\
\hline & Normal & 57 & 2,772 & Lazer & 16 & 3,188 \\
\hline & Trabalho & 23 & 2,304 & Saia mais & 18 & 3,222 \\
\hline & & & & Saúde & 13 & 4,538 \\
\hline & & & & Vida ativa & 30 & 3,633 \\
\hline \multirow{2}{*}{$\begin{array}{l}\text { Frequência } \\
\text { média }\end{array}$} & $\begin{array}{c}\text { Termos } \\
\text { evocados }\end{array}$ & \multirow{2}{*}{$\mathrm{F}$} & \multirow{2}{*}{ OME } & Termos evocados & \multirow[t]{2}{*}{$\mathrm{F}$} & \multirow{2}{*}{ OME } \\
\hline & $\begin{array}{l}\text { Elementos de } \\
\text { contraste }\end{array}$ & & & Segunda periferia & & \\
\hline$<12$ & $\begin{array}{l}\text { Fazia tudo } \\
\text { Má }\end{array}$ & $\begin{array}{l}7 \\
6\end{array}$ & $\begin{array}{l}2,571 \\
2,667\end{array}$ & $\begin{array}{l}\text { Afazeres domésticos } \\
\text { Autocuidado }\end{array}$ & $\begin{array}{l}6 \\
6\end{array}$ & $\begin{array}{l}2,833 \\
3,667\end{array}$ \\
\hline
\end{tabular}




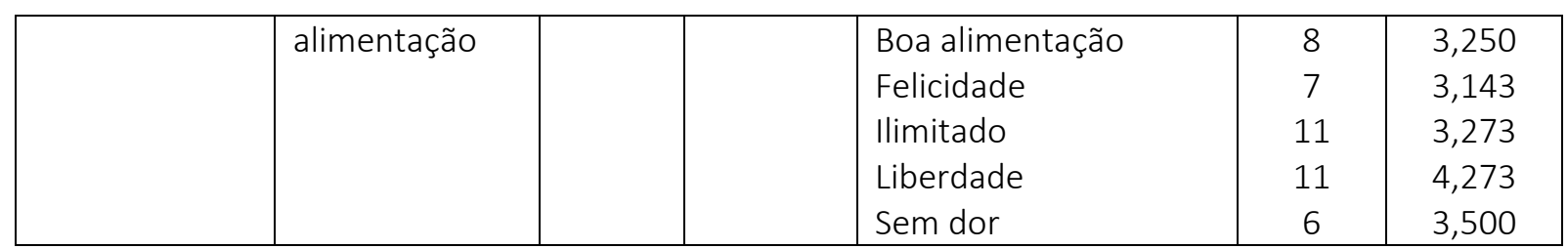

Nota: Ordem média das evocações (OME)

Fonte: dados da pesquisa.

Considerando o enunciado da Teoria do Núcleo Central, as palavras agrupadas no quadrante superior esquerdo são aquelas que tiveram as maiores frequências e foram mais prontamente evocadas, formando, portanto, por hipótese, o núcleo central da representação. Essas palavras caracterizam a parte mais consensual e constante da representação, assim como menos propício a mudanças em função do contexto externo ou das práticas diárias dos sujeitos. Isto mostra os discursos mais espontâneos dos participantes da pesquisa, uma vez que o ato da evocação traz à tona, a imaginação de algo que está presente na memória do indivíduo de maneira espontânea e que são equivalentes aos sistemas de crenças, valores e ideias destes sujeitos ${ }^{(13)}$.

As palavras localizadas no quadrante superior direito e no inferior esquerdo são consideradas elementos intermediários e podem se aproximar dos elementos centrais ou dos periféricos. Já as localizadas no quadrante inferior direito, integram o sistema periférico. Estes tem uma frequência menor de evocação, mas como maior ordem média, constituindo o pensamento preparado, ou seja, os sujeitos podem prepará-los intencionalmente antes de evocá-los. O quadro 1 nos mostra a seguinte distribuição das palavras: no quadrante superior esquerdo, temos as palavras boa, melhor, normal, trabalho, sendo estes os possíveis elementos centrais da representação; no quadrante superior direito estão as palavras da primeira periferia, são elas alegre, apoio-familiar, lazer, saia-mais, saúde e vida ativa; dentre os elementos de contraste, que se situam no quadrante inferior esquerdo, destacam-se fazia tudo e má alimentação; no quadrante inferior direito, temos as palavras que constituem-se como prováveis elementos periféricos da representação (segunda periferia), afazeres domésticos, autocuidado, boa alimentação, felicidade, ilimitado, liberdade e sem dor.

Acerca dos possíveis elementos do núcleo central é importante ressaltar que a palavra normal apresenta a maior frequência de evocações. Assim, este termo foi citado, ao todo, 57 vezes. No que se refere às outras palavras, boa possui a 35 evocações e o menor score $(1,943)$, indicando sua citação mais prontamente, a palavra trabalho foi citada 23 vezes e melhor 21 vezes. Estes elementos expressam o senso comum do grupo e direcionam os seus comportamentos e atitudes diante da qualidade de vida antes da ostomia. A observação deste quadrante nos leva a entender que esse grupo enxergava sua qualidade de vida de forma positiva antes da ostomia.

A palavra "normal" significa, entre outras definições, tudo que é permitido e aceito socialmente e diz-se da pessoa que não tem defeitos ou problemas físicos ou mentais ${ }^{(14)}$. Assim sendo, esse termo nos remete a uma visão positiva antes desse grupo ser submetido a uma ostomia.

Assim também como a palavra "boa", as pessoas estomizadas enxergavam sua qualidade de vida como sendo boa, sem alterações físicas ou emocionais que the causassem mal estar, e outras sensações.

Já o vocábulo "trabalho", que tem por significado, atividade profissional, regular, remunerada ou assalariada ${ }^{(14)}$. O trabalho é toda atividade física e cognitiva realizada pelo homem, com a finalidade de produzir riqueza, servindo como base às relações sociais. Ele atua como elo social do convívio fora do meio familiar, proporcionando relações de amizade, companheirismo, e até mesmo de competição, que unem os indivíduos e os mantêm em constante participação social ${ }^{(15)}$. 
Sendo assim, antes do estoma, as pessoas sentiam-se satisfeitas na profissão que exerciam, sem nenhum problema. No momento pós ostomia, a maioria se sente incapaz de voltar ao trabalho, fazendo com que muitas vezes ela vivencie sentimentos de nítida rejeição de si mesma, algumas vezes até como defesa antecipada da rejeição(16).

Já a palavra "melhor", que significa algo que é superior, por comparação com outro, em bondade, qualidade, caráter, importância e valor $^{(14)}$, nos remete a pensar em comparação entre a qualidade de vida antes e depois do estoma. Sendo melhor no período anterior ao estoma.

Entendemos o porquê dessa avaliação, pois o paciente não se sentia hostilizado e envergonhado como atualmente, tendo que passar por varias restrições, como se ele não fosse mesmo após o estoma. O sistema periférico da representação social se organiza em torno do núcleo central, constituído de elementos mais acessíveis, mais vivos e mais concretos, que possuem três funções primordiais, quais sejam: a de concretização, regulação e defesa da representação( ${ }^{(13)}$.

Os elementos da periferia que foram "afazeres domésticos", "autocuidado", "boa alimentação", "felicidade", "ilimitado", "liberdade" e "sem dor" apresentaram menor frequência e maior OME. Isso significa que foram palavras citadas que continham um pensamento mais elaborado. O termo "afazeres domésticos", muito utilizado pelo sexo feminino, nos mostra que essas pessoas não tinham dificuldade alguma em realizar suas tarefas diárias, e nem precisavam de auxilio para isto. Em consequência do uso da bolsa coletora, essas atividades se tornaram mais dificultosas, com limitações impostas pelo estoma, que acabam incomodando e influenciando no papel social, fazendo com que ele escolha a atividade que está apto a fazer ${ }^{(16)}$.

Orem $^{(17)}$, conceitua o autocuidado como sendo o desempenho ou prática de atividades que os indivíduos realizam em seu beneficio para manter a vida, a saúde e seu bem estar. Nessas pessoas o autocuidado era bem visível, no momento das evocações, eles relatavam que se cuidavam mais e que se sentiam bem consigo mesmo.

O termo "boa alimentação" nos revela que os mesmos antes acreditavam que sua alimentação estava boa, sem restrições, podiam comer tudo que queriam sem ser preocupar. Hoje em dia sua maior preocupação é com os alimentos que podem causar gazes e odor ou que são de rápida digestão, sendo muitos alimentos vetados. A alimentação é um aspecto muito importante, pois interfere na qualidade de vida das pessoas estomizadas ${ }^{(16)}$.

O termo "felicidade" significa estado de espírito de quem se encontra alegre ou satisfeito $^{(14)}$. Os entrevistados referiam ser bastante satisfeitos com sua qualidade de vida anterior ao estoma, sendo necessário que esta qualidade de vida seja vista como um bem maior a ser mantido e/ou recuperado, para que estas possam viver felizes e em harmonia no seu contexto de vida ${ }^{(18)}$.

O termo "ilimitado", juntamente com o termo "liberdade", nos remete a refletir sobre como era a qualidade de vida dessa pessoa, sem restrições e limites, podendo fazer de tudo sem preocupações. O processo do estoma, revelase uma experiência traumatizante na vida das pessoas, não só pelas limitações, como dito acima, mas também pelos temidos constrangimentos que estão associados ao viver para toda a vida com um estoma ${ }^{(16)}$.

Já o termo "sem dor" significa que esta pessoa não sentia as dores que sente agora, nos levando a acreditar que a dor surgiu no momento em que o diagnóstico foi revelado, pois o impacto foi grande, em descobrir que estar com câncer e a necessidade da realização do estoma ${ }^{(19)}$.

Os elementos intermediários podem se aproximar do núcleo central ou da periferia, são eles: alegre, apoio familiar, lazer, saia mais, saúde e vida ativa. O termo "alegre", que significa aquele sente, tem ou expressa alegria; contente, se aproxima do termo felicidade, como dito anteriormente essas pessoas tinham mais motivos para se alegrar, isto era notoriamente percebido no momento da entrevista. Para muitos a vida acabou ali, no momento da colostomia, onde perderam totalmente sua vontade de viver e se alegrar. 
"Apoio familiar" foi o único termo presente no mesmo quadrante, antes e após o estoma, nos mostrando como esse apoio é importante e essencial mesmo antes do diagnóstico. A família é o primeiro grupo social do paciente, desempenhando papel fundamental de apoio em todas as fases enfrentadas pelo mesmo ${ }^{(19)}$. Sendo assim, o apoio dos familiares e a cumplicidade entre paciente e familiar são as bases para lidar com qualquer situação vivenciada ${ }^{(20)}$.

Os termos "lazer" e "saia mais" foram utilizados para expressar as atividades que os mesmos faziam para se distrair e se divertir, referidos pelos mesmos como pescar, bordar, viajar, nadar, correr entre outros, sendo muito difícil voltar a fazer após o estoma. Essas atividades proporcionam ao indivíduo distração e reinserção social, ajudando-o a sentir-se normal como os que o cercam. A pessoa estomizada procura formas de retomar as atividades sociais, interpessoais e de lazer, anteriores à cirurgia que contribuem para sua reabilitação e reinserção social ${ }^{(15)}$.

Com relação ao vocábulo "saúde", os pacientes relatavam que se sentiam com mais saúde no período anterior ao estoma, período em que referiram estar em perfeito estado de saúde, que repentinamente foi transformado em uma nova realidade cheia de restrições ${ }^{(21)}$. Com o diagnóstico a condição de saúde do individuo, caracteriza-se como sendo uma situação crônica, ao longo da sua vida, fazendo necessário que a mesma desenvolva estratégias que lhe permita aprimorar competências de autocuidado, convivência social, de forma a aprender a viver e a gerir a situação do processo saúde-doença ${ }^{(16)}$.

A expressão "vida ativa", diz respeito aos relacionamentos afetivos que os mesmo possuíam, o fato de sair, ter um encontro, entre outros. Com o advento do estoma esses interesses acabaram ficando em segundo plano inicialmente. Não apenas pela sexualidade, pois, ela excede a necessidade fisiológica e tem relação direta com a simbolização do desejo e da atração ${ }^{(21)}$. Na maioria dos pacientes estomizados a atividade sexual e a sexualidade sofrem dificuldades devido à própria cirurgia e as alterações na imagem corporal. Pessoas com relacionamentos estáveis a percebiam de forma positiva, como necessidade física e emocional a ser partilhada, e aquelas em que os relacionamentos apresentavam problemas prévios à confecção do estoma atribuíram significados negativos, negando ou evitando-a(22).

Os elementos de contraste são "fazia tudo" e "má alimentação". E são elementos que podem se aproximar dos elementos centrais ou dos periféricos. Com relação ao termo "fazia tudo", os entrevistados se referiam ao fato de não ter restrições a nenhum tipo de atividade, podiam fazer de tudo sem se preocupar com a saúde ou com o esforço físico. "Má alimentação" nos leva a refletir sobre o hábito alimentar que os mesmos tinham, os costumes de comer alimentos gordurosos, alta ingestão de sal, alimentos com poucas fibras e, de repente, se viram forçados a mudar radicalmente seus hábitos alimentares ${ }^{(16)}$.

Por sua vez, a análise da qualidade de vida após o estoma evidenciou 800 palavras evocadas, com 115 diferentes. A ordem média de evocações foi 3,3, e a frequência mínima foi de 13, com a seguinte estrutura de quadro de quatro casas.

Quadro 2. Estrutura da representação social da qualidade de vida após a colostomia. Rio de Janeiro, RJ, Brasil, 2016.

\begin{tabular}{|c|c|c|c|c|c|c|}
\hline \multicolumn{7}{|c|}{ OME $(n=80)$} \\
\hline \multicolumn{4}{|c|}{$<3,3$} & \multicolumn{3}{|c|}{$\geq 3,3$} \\
\hline \multirow{3}{*}{$\begin{array}{l}\text { Frequência } \\
\text { média }\end{array}$} & Termos evocados & \multirow{3}{*}{$\mathrm{F}$} & \multirow{3}{*}{ OME } & Termos evocados & \multirow{3}{*}{$\mathrm{F}$} & \multirow{3}{*}{ OME } \\
\hline & & & & & & \\
\hline & $\begin{array}{c}\text { Elementos } \\
\text { centrais }\end{array}$ & & & Primeira periferia & & \\
\hline \multirow{3}{*}{$\geq 13$} & Medo & 22 & 3,227 & Aceitação & 23 & 3,609 \\
\hline & Não faço nada & 25 & 3,240 & Adaptação & 13 & 3,308 \\
\hline & & & & Apoio familiar & 24 & 4,125 \\
\hline
\end{tabular}




\begin{tabular}{|c|l|l|l|l|l|l|}
\hline \multirow{2}{*}{$\begin{array}{c}\text { Frequência } \\
\text { média }\end{array}$} & Termos evocados & \multirow{2}{*}{$\mathrm{F}$} & OME & Termos evocados & \multirow{2}{*}{$\mathrm{F}$} & OME \\
\cline { 2 - 2 } & $\begin{array}{c}\text { Elementos de } \\
\text { contraste }\end{array}$ & & & Segunda periferia & & \\
\hline \multirow{3}{*}{$<13$} & Dificuldade & 11 & 1,818 & Boa & 10 & 4,300 \\
& Incômodo & 11 & 2,818 & Dor & 10 & 3,700 \\
& Limitado & 12 & 2,667 & Estou vivo & 08 & 3,875 \\
& Mudança de vida & 11 & 3,000 & Superação & 10 & 3,500 \\
& Nada mudou & 10 & 2,100 & Tristeza & 10 & 3,700 \\
& Normal & 09 & 1,778 & Vergonha & 12 & 3,333 \\
\hline
\end{tabular}

Nota: Ordem média das evocações (OME)

Fonte: dados da pesquisa.

O Quadro 2 nos mostra a seguinte distribuição das palavras: no quadrante superior esquerdo, temos as palavras medo, não faço nada, sendo estes os possíveis elementos centrais da representação; no quadrante superior direito estão as palavras da primeira periferia, são elas aceitação, adaptação, apoio-familiar; dentre os elementos de contraste, que se situam no quadrante inferior esquerdo, destacam-se dificuldade, incômodo, limitado, mudança de vida, nada mudou, normal; no quadrante inferior direito, temos as palavras que constituem-se como prováveis elementos periféricos da representação (segunda periferia), boa, dor, estou vivo, superação, tristeza, vergonha.

Acerca dos possíveis elementos do núcleo central é importante ressaltar que a expressão não faço nada apresenta a maior frequência de evocações. Assim sendo, este termo foi citado, ao todo, 25 vezes. No que se refere às outras palavras, medo possui 22 evocações e o menor score $(3,227)$, indicando que foi citado mais prontamente. Como dito anteriormente, estes elementos expressam o senso comum do grupo e direcionam os seus comportamentos e atitudes diante da qualidade de vida antes da ostomia.

A observação das palavras do núcleo central expressam posicionamentos negativos dos sujeitos acerca da qualidade de vida após a ostomia.

A expressão "não faço nada" reflete que este paciente não se sente capaz de realizar nenhuma atividade, podendo ser também em consequência do medo. Pessoas submetidas ao estoma tem dificuldades ao retorno de suas

atividade diárias, fazendo com que permaneçam grande parte do tempo em casa, ociosos e sentindo-se inválidos e por isso incapazes de realizar alguma atividade ${ }^{(28)}$.

Durante todo o processo, afloram também sentimentos de inferioridade e incapacidade, que podem interferir no processo de desenvolvimento do cotidiano, configurando-se em isolamento social, podendo repercutir tanto no trabalho como no lazer ${ }^{(23)}$

Os sentimentos de inutilidade, inferioridade, desgosto, perda da autoestima e do status social, além de provocarem alterações na dinâmica familiar, causam impacto psicológico, nutrem a ideia de que perderão sua capacidade produtiva, levando-os a expressar sentimentos como tristeza, ódio, repulsa e medo ${ }^{(24)}$.

A palavra "medo" está relacionada a insegurança que este paciente sente, por tratar de uma situação totalmente nova e diferente para ele, e por temer algum tipo de rejeição pelo outro. A pessoa que passa por este processo sente-se inseguro quanto ao manejo do dispositivo coletor e aos cuidados com a ostomia, sentimento que está associado a possibilidade de ocorrer vazamentos da bolsa e exalação de odores ${ }^{(17)}$.

A experiência de estar com câncer e ter um estoma causam impactos e sofrimento em função dos valores e crenças presentes na sociedade. Viver a essa experiência é confrontar os valores e 
as crenças do grupo com os valores e crenças pessoais $^{(5)}$.

O sistema periférico da representação social, conforme citado anteriormente, se organiza em torno do núcleo central, constituído de elementos mais acessíveis e mais concretos, que possuem três funções primordiais: a de concretização, regulação e defesa da representação(13).

Os elementos da periferia foram: boa, dor, estou vivo, superação, tristeza e vergonha apresentaram menor frequência e maior OME. Isso significa que foram palavras pouco citadas pelos pacientes porém com uma maior ordem de evocação, constituindo um pensamento mais elaborado.

A palavra "boa" evidencia que, apesar de toda essa mudança de vida, os estomizados ainda consideram a qualidade de vida boa, reagindo de forma diferente, reconhecendo o estoma como uma coisa normal, um fator que vai ajudar e não prejudicar, de forma a minimizar o sofrimento, demonstrando aceitação e habituação a condição atual $^{(23)}$.

Já o termo "dor", que significa sensação desagradável ou penosa, causada por um estado anômalo do organismo ou parte dele ${ }^{(14)}$, nos fazem perceber o que esse paciente sente, seja uma dor física resultado de uma intervenção cirúrgica e/ou uma dor emocional de ver seu corpo mutilado e tendo um caminho diferente para eliminação das fezes.

As sequelas, os tratamentos e as complicações decorrentes da cirurgia acabam por levar a sintomas como dores, vômitos, cefaleia, mal estar, infecções, influenciando no não retorno da pessoa à vida ativa(15). A dor neste paciente reveste-se de características especiais, nesse sentido, a dor agregada à condição vivenciada transforma a vivência em algo que favorece a aflição e o sofrimento, ultrapassando a dimensão física afetando assim os âmbitos psicológico e social ${ }^{(24)}$.

A dor provocada pela assadura, causada pelo contato da excreção com a pele, somando-se sentimentos de ansiedade e insegurança, relacionados ao medo de descolar, "estourar" a bolsa em local público, restringe e muito a qualidade de vida da pessoa estomizada. A melhor forma de tratamento é a prevenção, com a necessidade da participação dos profissionais especializados contribuindo na redução dessa complicação(23).

Nesse sentido a enfermagem pode contribuir no cuidado prestado a esses estomizados, no que diz respeito a monitorar a ostomia visando detectar possíveis complicações, avaliar a eficácia do dispositivo colocado, observando sinais de irritação ou falha de aderência, ensinar o autocuidado e lidar com as reações do ostomizado ${ }^{(23)}$.

A expressão "estou vivo", que teve a menor frequência de evocações desse quadrante, nos faz entender que apesar de todas as situações que ele passou, ele ainda está vivo, sendo um elemento positivo de dimensão avaliativa. Estes pacientes aceitam o estoma por falta de opção, enfatizando que mesmo sendo difícil conviver com a bolsa, eles estão vivos e não se sentem mais doentes, com dor ou com possibilidade de morte iminente ${ }^{(19)}$.

Observa-se um balanço entre o que se perdeu e o que se ganhou, no qual um desvio intestinal e todas as dificuldades sentidas são de certa forma amenizada, pelo fato de estarem com vida e com alguma qualidade de vida ${ }^{(16)}$.

O termo "superação", que também é um elemento da dimensão avaliativa, nos faz entender que, para que houvesse o processo de superação foi necessário o uso de ferramentas de enfrentamento como: religião, família entre outros. Com o decorrer do tempo, dependendo da evolução da doença e das possibilidades de adaptação encontradas, o estomizado cria ferramentas que o ajudarão a enfrentar essa nova forma de viver, de superar os desafios e aceitar a sua nova realidade, de forma a se adaptarem e alcançarem a melhor qualidade de vida que lhes seja possível.

A existência de pessoas que conseguem enfrentar ainda mais dificuldades os faz acreditar que é possível superar as suas próprias adversidades ${ }^{(23-24)}$.

A palavra "tristeza" que se projeta como um elemento negativo de dimensão avaliativa nos reforça a ideia de que as reações e sentimentos das pessoas estomizadas são fortemente influenciados pelos aspectos valorizados em nossa cultura como 
saúde, a valorização do corpo perfeito e vida. Esses princípios são as referências pelos sentimentos de tristeza, depressão, sofrimento, medos e incertezas e, principalmente, pela impotência frente à declaração da finitude da vida, que acompanha essas pessoas ${ }^{(15)}$.

Essas pessoas além de terem que viver com uma dor intensa, em consequência do procedimento cirúrgico, necessitava ainda conviver com o sofrimento de seus familiares, o que intensificava ainda mais seu sentimento de tristeza ${ }^{(16)}$.

O termo "vergonha" é utilizado para expressar a perda da conotação do corpo de ser e ficar íntegro, passando a ter uma configuração diferente e aspecto de sujo. A presença do estoma provoca alterações da imagem que a pessoa tinha do seu corpo, manifestando assim, o sentimento de vergonha de um corpo alterado e mutilado, com receio de voltar ao convívio familiar e social, interferindo assim nas atividades que realizava antes do estoma ${ }^{(18)}$.

Os elementos intermediários podem se aproximar do núcleo central ou da periferia, são eles: aceitação, adaptação e apoio familiar.

A palavra "adaptação" se aproxima tanto do núcleo central quanto dos elementos da periferia, pode ser definida como ação ou efeito de adaptar-se; de aprender a conviver com uma situação inusitada proveniente, nesse caso, de um agravo à saúde visando a reabilitação da saúde. A adaptação, portanto, baseia-se, no processo através do qual a pessoa se ajusta às condições do meio, percebidas por esta, como adversas, com o intuito de garantir sua integridade física, psicológica e social|(19).

O paciente submetido a ostomia vai necessitar passar por períodos de adaptação, pois com a perda do controle de parte de seu corpo, que antes funcionava de forma autônoma, o mesmo vai vivenciar sentimentos diversos e, muitas vezes assustadores diante desta nova situação. A visão deste paciente sobre o uso da bolsa coletora implica em questões relacionadas a mudanças drásticas em seu cotidiano, e representa um desafio para sua adaptação a esta nova realidade ${ }^{(24)}$.

A palavra "aceitação", que tem por significado ato ou efeito de aceitar/concordar ${ }^{(14)}$, se aproxima do elemento de periferia superação, partindo do principio que para haver superação, precisa passar primeiro pela aceitação.

As mudanças que ocorrem na vida do estomizado são muitas e também difíceis de aceitar, principalmente porque são situações desagradáveis e que alteram o cotidiano desse paciente, como o incômodo causado quando há vazamento, eliminação de gases e odor das fezes. Sem dúvida alguma, isso representa um grande desafio, pois necessitam encontrar alternativas para minimizar as situações desagradáveis. Exigindo assim, da pessoa estomizada a adoção de inúmeras medidas de adaptação e reajuste nas atividades do cotidiano, incluindo o aprendizado das ações de autocuidado do estoma e da pele no periestoma, no intuito de evitar ou minimizar possíveis problemas ${ }^{(18)}$.

Diversas vezes, o paciente demonstra dificuldades na própria aceitação e no processo de adaptação, necessitando de um tempo interno para viver o seu momento de luto, ou seja, reconsiderar os seus conceitos, reavaliar suas perdas e encontrar forças para aceitar e trabalhar suas novas possibilidades após o uso da bolsa de colostomia $^{(23)}$.

A aceitação é um processo contínuo entre a pessoa e a sua nova condição de vida. Trata-se de um meio particular, que varia de pessoa para pessoa, sendo mais ou menos prolongado, dependendo dos recursos disponíveis para cada um enfrentar a condição de pessoa estomizada ${ }^{(25)}$. Existem fatores que são determinantes para a aceitação, dentre eles o apoio familiar e a contribuição da assistência da equipe multidisciplinar ${ }^{(22)}$.

O termo "apoio familiar" destaca-se como fundamental para o enfrentamento da doença. A família é percebida como unidade de cuidado em que se estreitam os laços de solidariedade. É a fonte de ajuda que contribui para o bem-estar e o estar melhor da pessoa com ostomia. Podem possuir laços sanguíneos ou emocionais, compartilhando ou não o mesmo ambiente e são influenciados, e influenciam, pela experiência de conviverem com seu familiar estomizado. A família, percebida como primeiro núcleo social do indivíduo exerce profunda influência nas reações que ele pode ter diante de situações de crise ou 
daquelas que determinam alterações na rotina de sua vida(19).

O apoio familiar, demonstrado através dos cuidados físicos, psicológicos e sociais adequados, auxilia de forma precisa na recuperação da pessoa estomizada. As reações positivas também são essenciais nesta fase, assim como sua reinserção nas atividades sociais e do cotidiano ${ }^{(29-20)}$.

Sendo assim, acredita-se que o apoio familiar dado à pessoa estomizada é fundamental, sendo muito importante para a aceitação da ostomia e, consequentemente, para o seu processo de reabilitação e adaptação, oferecendo proteção, conforto e afeto ao paciente ${ }^{(19)}$.

Os elementos de contraste são: dificuldades, incômodo, limitado, mudança de vida, nada mudou e normal. São elementos que podem se aproximar dos elementos centrais ou dos periféricos. O vocábulo "dificuldades" tem significado de natureza do que é difícil; situação bastante difícil. Podemos relacionar essas dificuldades à falta de informação, demonstração prática dos diversos tipos de dispositivos para a ostomia, afastamento das relações sociais, incapacidade para o autocuidado, constrangimentos econômicos e financeiros na obtenção de recursos sociais e apoio emocional ${ }^{(16)}$. Apesar da ostomia ser realizada com o intuito de salvar vidas, ele também pode gerar diversas dificuldades aos indivíduos submetidos à mesma, tais como: mudanças corporais e sociais, alimentares, vestuário, desempenho de papéis e sexualidade, podendo causar transtornos psicológicos levando à ansiedade, angústia, depressão e vergonha, acarretando assim, um isolamento social do indivíduo(15).

Os limites e dificuldades trazidos no viver com o estoma também estão presentes e relacionam-se à: assadura e irritação na pele, restrição alimentar, restrições físicas, medo de descolar e "estourar" a bolsa em local público(19).

Observa-se também dificuldades em relação ao retorno às atividades de lazer, que em muitos casos esses pacientes não retomam suas atividades e quando fazem é apenas de modo parcial, por insegurança relacionada a qualidade dos dispositivos, ou ainda por medo de problemas gastrintestinais. Dificuldades também relacionadas a volta ao trabalho, pois se sentem inseguros para continuar cuidando do estoma e ainda trabalhar. Em decorrência disso, alguns acabam pedindo aposentadoria por invalidez, o que representa um problema econômico em virtude dessas pessoas serem muitas vezes as provedoras da família, fato que causa um desequilíbrio e mudanças no padrão de vida, além de ser mais um fator que causa problemas psicológicos para o paciente ${ }^{(21)}$.

Já a palavra "incômodo" pode ser entendida como algo que incomoda, que não oferece conforto. Sendo assim, as preocupações dessa população se concentram no uso da bolsa e dos incômodos decorrentes deste, como eliminação de gazes, vazamento e odor das fezes $^{(15)}$.

O termo "limitado" nos dá a ideia de limites, algo com limites restritos, e nesse sentido, é assim que vive a pessoa com o estoma, limitado em diversas áreas da sua vida(16). O próprio estoma pode representar uma limitação ao projeto de vida destas pessoas e sendo o impacto da mudança de vida grande, pois os mesmos encontravam-se em ótimo estado de saúde e inesperadamente são obrigados a mudar radicalmente seus hábitos de vida(21).

Essas limitações acabam incomodando e influenciando no papel social, pelo fato dessas barreiras prejudicarem em diversos âmbitos da vida, como na alimentação, na forma de se vestir, na sexualidade e na vida social, fazendo com que o indivíduo selecione as atividades que podem ser realizadas ou fazendo com que permaneça a maior parte do tempo em casa. Ficam expostos ao contato com a deformação física, vivenciam sentimentos de baixa autoestima, e também, é o momento que a pessoa passa a tomar consciência das limitações em suas atividades da vida diária, gerando um sentimento de inconformismo ${ }^{(22)}$.

O vocábulo "mudança de vida" está relacionado com as mudanças ocorridas na vida do estomizado após o estoma. A experiência vivenciada pela pessoa estomizada está relacionada com a mudança que ocorre em sua vida, em sua saúde, nas relações sociais e nos ambientes. Todo esse processo exige que a pessoa incorpore novos conhecimentos, altere comportamentos, atitudes e também o conceito de si mesmo. Viver com uma ostomia determina mudanças de vida permanentes na vida diária da 
pessoa e família, constituindo, assim, um dos momentos mais críticos no percurso da sua vida ${ }^{(16)}$.

Diversas vezes o indivíduo não sabe como conviver com essas mudanças que ocorrem, principalmente com a aparência corporal, como é o caso da diminuição brusca e acentuada de peso, visto que o mesmo passa por restrições alimentares rigorosas, sendo indispensável o apoio da família nessas ocasiões ${ }^{(15-21)}$.

O termo "nada mudou" se mostra como um elemento positivo, nos fazendo entender que mesmo com todas as mudanças ocorridas ao longo do processo, muitos pacientes encaram a vida do mesmo modo quando não usavam a colostomia. É um processo de reconhecimento que implica em sentir o que mudou ou não, e as diferenças ocorridas durante o processo de transição, refletindo em seu bem estar ${ }^{(16)}$.

Já a palavra "normal", assim como o termo "nada mudou", também se mostra como um elemento positivo, seu significado, segundo o dicionário online, diz-se da pessoa que não tem defeitos; tudo que é permitido e aceito socialmente. Passado o choque inicial, e depois do período de adaptação, o paciente estomizado, pode e deve levar uma vida normal, sempre respeitando alguns pontos fundamentais e utilizando materiais adequados para conseguir a segurança que necessita ${ }^{(23)}$.

É possível observar também uma determinação por parte de algumas pessoas, em retomar a normalidade em suas vidas, da mesma forma como anteriormente viviam, tendo em conta, no entanto, as especificidades resultantes da presença de um estoma(18).

Fazendo uma comparação entre o antes e o depois do estoma, foi claramente possível ver suas diferenças, principalmente em relação aos sentimentos, suas limitações, seus hábitos alimentares, seus medos e estigmas. Para muitos realmente a vida acaba com o estoma, para outros a vida começa de uma forma diferente, cheio de força de vontade e superação, e isso significa ser resiliente, ou seja, eles foram capazes de enfrentar e responder de forma positiva às adversidades e suas consequências potencialmente negativas ${ }^{(23)}$.

A enfermagem, assim como outros profissionais possuem participação importante nesse processo de adaptação, cada um vai atuar integradamente, somando benefícios ao principal alvo de nossos cuidados, o estomizado. Dessa forma, sua reabilitação é facilitada, como também a aceitação da nova imagem corporal e a realização do autocuidado(20).

\section{Conclusão}

Ao longo de todo o percurso vivido, o indivíduo estomizado se defronta com várias alterações no seu cotidiano, as quais não atingem somente ao nível fisiológico, mas também ao nível psicológico, físico, espiritual, social e sexual, o que repercute radicalmente na qualidade de vida. Logo, necessitam de atenção e compreensão em seus múltiplos aspectos, considerando todo o período de reabilitação. Essa atenção em saúde deve ser prestada desde o período pré-operatório, englobando os significados e concepções do indivíduo, da sua família e de suas relações sociais.

A enfermagem nesse caso é importante para auxiliar tanto física, como psiquicamente na aceitação desta nova realidade, orientando e treinando o individuo e família na escolha do equipamento adequado, informando-os quanto às dietas alimentares, discutindo e tirando duvidas relacionados ao estoma, colaborando para uma melhora gradativa da qualidade de vida e auxiliando no ensinamento do autocuidado, promovendo assim a saúde e prevenindo outras doenças.

Para o estomizado, qualidade de vida será o alcance máximo de bem estar e autonomia. Sendo assim, faz-se necessário a implantação e permanência de uma equipe multidisciplinar que vise a reinserção social, fornecendo estratégias para melhor adaptação da sua nova condição de vida, repriorizando valores e metas.

Essas pessoas são capazes de retomar suas atividades sempre respeitando os limites infligidos pela sua nova condição. Esperamos que este estudo venha promover conhecimento sobre a qualidade de vida desse paciente, contribuindo para uma relação completa e satisfatória.

Os objetivos inicialmente propostos para a realização deste trabalho foram alcançados na medida em que permitiram a compreensão das representações da qualidade de vida da pessoa que vive com um estoma, em decorrência do câncer. 
Conhecer a representação da qualidade de vida dessas pessoas foi e será um importante caminho aos profissionais enfermeiros para melhor entender aqueles a quem prestarão o cuidado, colaborando assim na sua qualificação e atendimento a todos com eficiência e de forma humanizada, possibilitando que no futuro mais estudos sobre essa população possam ser realizados.

\section{Referências}

1. Ministério da Saúde (BR). Resenha da luta contra o câncer no Brasil: documentário do serviço nacional de câncer/Ministério da Saúde. - 2. ed. Brasília: Ministério da Saúde [Internet]. 2007 [acesso em 15 jan 2016]. Disponível em: http://bvsms.saude.gov.br/bvs/publicacoes/resen ha_luta_contra_cancer.pdf.

2. Instituto Nacional de Câncer José Alencar Gomes da Silva (BR). Coordenação de Prevenção e Vigilância Estimativa 2016: Incidência de Câncer no Brasil/Instituto Nacional de Câncer José Alencar Gomes da Silva, Coordenação de Prevenção e Vigilância. Rio de Janeiro: INCA [Internet]. 2016 [acesso em 15 jan 2016]. Disponível em: http://www.inca.gov.br/wcm/dncc/2015/estimati va-2016.asp.

3. Fernandes I. Guia do estomizado. Federação gaucha de Estomizados - FEGEST [Internet]. 2016 [acesso em 30 jan 2016]. Disponível em: www.fegest.org.

4. Torres CRD, Andrade EMLR, Ribeiro FMSS, Gonçalves Neta FCC, Luz MHBA. Quality of life of stomized people: an integrative review. Rev Enferm UFPI [Internet]. 2015 [acesso em 24 jan 2016]; 4(1):117-22. Disponível em: http://www.ojs.ufpi.br/index.php/reufpi/article/vi ew/2242/pdf.

5. Moscovici, S. (1978). A representação social da psicanálise. Rio de Janeiro: Zahar. In: Vieira KFL, Reis ID, Morais Segundo JB, Fernandes ME, Macdonald TTV. Representações sociais da qualidade de vida na velhice. Psicologia: ciência e profissão [Internet]. 2012 [acesso em 02 fev 2016];
32(3):540-551. Disponível em: http://www.scielo.br/scielo.php?script=sci_arttext \&pid=S141498932012000300002\&lng=en\&nrm=i so.

6. Sales CA, Violin MR, Waidman MAP, Marcon SS, Silva MAP. Sentimentos de pessoas ostomizadas: compreensão existencial. Rev. esc. enferm. USP [Internet]. 2010 [acesso em 02 fev 2016]; 44(1):221-227. Disponível em: http://www.scielo.br/scielo.php?script=sci_arttext \&pid=S0080-62342010000100031\&lng=en.

7. Sá CP. Núcleo central das representações sociais. Petrópolis: Vozes; 2002.

8. Guimarães RM, Muzi CD, Boccolini CS, Boccolini PMM, Boeira SF. Tendência da mortalidade por câncer de cólon e reto no Brasil segundo sexo, 1980-2009. Cad Saúde Colet [Internet]. 2012 [acesso em 20 dez 2016]; 20(1):121-7. Disponível em:

http://www.cadernos.iesc.ufrj.br/cadernos/image s/csc/2012_1/artigos/CSC_v20n1_121-127.pdf.

9. Cunha RR, Ferreira AB, Backes VMS. Características sóciodemográficas e clínicas de pessoas estomizadas: revisão de literatura. Rev. Estima [Internet]. 2013 [acesso em 22 dez 2016]; 11(2). Disponível em: https://www.revistaestima.com.br/index.php/esti $\mathrm{ma} /$ article/view/327.

10. Luz ALA, Luz MHBA, Antunes A, Oliveira GS, Andrade EMLR, Miranda SM. Perfil de pacientes estomizados: revisão integrativa de literatura. Cultura de los cuidados [Internet]. 2014 [acesso em 02 jan 2017]; 18(39). Disponível em: http://culturacuidados.ua.es/article/view/2014n39-perfil-de-pacientes-estomizados-revisaointegrativa-da-literatura.

11. Moraes JT, Victor DR, Abdo JR, Santos MC, Perdigão MM. Caracterização dos estomizados atendidos pela Secretaria Municipal de Saúde de Divinópolis - MG. Rev Estima [Internet]. 2009 [acesso em 03 jan 2017]; 7(3). Disponível em: https://www.revistaestima.com.br/index.php/esti $\mathrm{ma} /$ article/view/52. 
12. Silva AC, Silva GNS, Cunha RR. Caracterização de pessoas estomizadas atendidas em consulta de Enfermagem do serviço de Estomaterapia do Município de Belém - PA. Rev Estima [Internet]. 2012 [acesso em 03 jan 2017]; 10(1). Disponível em:

https://www.revistaestima.com.br/index.php/esti ma/article/view/72.

13. Abric JC. A abordagem estrutural das representações sociais. In: Moreira ASP, Oliveira DC. organizadoras. Estudos interdisciplinares de representação social. 2. ed. Goiânia: AB Editora; 2000.

14. Dicionário de português online [Internet]. [acesso em 05 jan 2017]. Disponível em: http://michaelis.uol.com.br.

15. Reis, FF. Transição para a vivência com uma ostomia: intervenções de enfermagem. [Tese] Faculdade de Enfermagem, Universidade do Porto: Porto; 2015.

16. Ribeiro CO, Muniz RM, Furtado SMSR, Viegas AC, Amaral DED. Descobrindo o mundo estomizado: vivência das pessoas com o dispositivo. Rev. Estima [Internet]. 2015 [acesso em 03 jan 2017]; 13(1). Disponível em: https://www.revistaestima.com.br/index.php/esti ma/article/view/100.

17. Orem DE. Nursing: concepts of practice. New York, Mac Graw-Hill, 1971. 23 2p. In: Fernandes, CR. Fundamentos do processo: saúde, doença, cuidado. Rio de Janeiro: Águia Dourada; 2010.

18. Cesaretti IUR, Santos VLCG, Vianna LAC. Qualidade de vida de pessoas colostomizadas com e sem uso de métodos de controle intestinal. Rev Bras Enferm [Internet]. 2010 [acesso em 03 jan 2017]; 63(1):16-21. Disponível em: http://www.scielo.br/scielo.php?script=sci_arttext \&pid=S0034-71672010000100003\&lng=en.

19. Oliveira G, Maritan CVC, Mantovanelli C, Ramalheiro GR, Gavilhia TCA, Paula AAD. Impacto da estomia: sentimentos e habilidades desenvolvidos frente à nova condição de vida. Rev. Estima [Internet]. 2010 [acesso em 03 jan 2017]; 8(1):18-24. Disponível em: https://www.revistaestima.com.br/index.php/esti ma/article/view/55.

20. Mirand SM, Nascimento CMFS, Luz MHBA, Andrade EMLR, Luz ALA, Torres CRD. Viver com estomia: contribuições para a assistência de enfermagem. Rev. Estima [Internet]. 2014 [acesso em 05 jan 2017]; (12)3. Disponível em: https://www.revistaestima.com.br/index.php/esti ma/article/view/94.

21. Kimura CA, Kamada I, Fortes RC, Sadi PM. Reflexões para os profissionais de saúde sobre a qualidade de vida de pacientes oncológicos estomizados. Com Ciências Saúde [Internet]. 2009 [acesso em 05 jan 2017]; 20(4):333-40. Disponível em:

http://www.escs.edu.br/pesquisa/revista/2009Vol 20_4art7reflexoes.pdf.

22. Paula MAB; Takahashi RF; Paula PR. Os significados da sexualidade para a pessoa com estoma intestinal definitivo. Rev bras. colo-proctol [Internet]. 2009 [acesso em 06 jan 2017]; 29(1):77$82 . \quad$ Disponível em: http://www.scielo.br/scielo.php?script=sci_arttext \&pid=S0101-98802009000100011\&lng=en.

23. Couto PG; Medeiros SS. Sentimentos da pessoa submetida a ostomia intestinal - uma visão holística de enfermagem. Rev Clin Hosp Prof Dr Fernando Fonseca [Internet]. 2013 [acesso em 06 jan 2017]; 2(1):23-27. Disponível em: https://revistaclinica.hff.min saude.pt/index.php/rhff/article/view/38.

24. Vieira LM, Ribeiro BNO, Gatti MAN, Simeão SFAP, Conti MHS, Vitta A. Câncer colorretal: entre o sofrimento e o repensar na vida. Saúde Debate [Internet]. 2013 [acesso em 06 jan 2017]; 37(97). Disponível em: http://www.scielo.br/scielo.php?script=sci_arttext \&pid=S0103-11042013000200008\&lng=en. 